\title{
EVALUATING MEASURES OF MARKET RISK IN CIRCUMSTANCES OF GLOBAL FINANCIAL CRISIS - EMPIRICAL EVIDENCE FROM FIVE COUNTRIES
}

Ivica Terzić, Marko Milojević, Singidunum University, mmilojevic@ singidunum.ac.rs

The purpose of this paper is to evaluate performance of value-at-risk (VaR) produced by two risk models: historical simulation and Risk Metrics. We perform three backtest: unconditional coverage, independence and conditional coverage. We present results on both $\mathrm{VaR} 1 \%$ and $\mathrm{VaR} 5 \%$ on a one-day horizon for the following indices: S\&P 500, DAX, SAX, PX and Belex 15. Our results show that Historical simulation 500 days rolling window approach satisfies unconditional coverage for all tested indices, while Risk Metrics has many rejection cases. On the other hand Risk Metrics model satisfies independence backtest for three indices, while Historical simulation has rejected more times. Based on our strong criteria to accept accuracy of VaR models only if both unconditional coverage and independence properties are satisfied, results indicate that during the crisis period all tested VaR models underestimate the true level of market risk exposure.

JEL Classification Numbers: G17, G32, C53, DOI: 10.12955/cbup.2013.17

Keywords: value at risk, backtesting, market risk, historical simulation, risk metrics

\section{Introduction}

Risk is an integral part of human existence and wherever there is a human activity the risks are present. The idea that risk, from a scientific point of view, may be important to the economy is dating back from 1921 in the paper Frank H. Knight Risk, Uncertainty and Profit. Financial risk includes situations where there is uncertainty and opportunity for achievement's financial loss or in other words, this risk is related to the money that can be lost in the financial markets. The development of the financial sector makes a lot of innovation in the field of financial risk management, especially in the modeling of market, credit and operational risk. The main measure of market risk is value at risk (VaR) methodology, which measures the worst loss potential when holding a financial asset over specific time period with a certain probability, and which is in practice used with other techniques to minimize the risks in order to achieve good results in business.

We believe the use of multiple risk models both fundamental and statistical can help managers to predict portfolio risk more accurately, provide a more comprehensive view of portfolio risks and can help managers to react faster and with more confidence. The financial crisis and its aftermath clearly resulted in variations in predicted risk. Our goal is to show that using of VaR models can underestimate market risk in both developing stock market and especially in transition stock markets. Many models can be used to estimate market risk but they must satisfy two properties: unconditional coverage and independence. 
The purpose of this paper is to discuss and provide an answer weather Historical simulation (HS) and Risk Metrics (RM) as an approaches for measuring VAR significantly underestimates market risk in analyzed capital markets during market stress circumstances.

Measuring of market risk in Serbian Belgrade Stock Exchange (BSE) has not been as extensively studied as some countries of former Republic Yugoslavia. Žiković analyses the benefits of using time weighted historical simulation (BRW approach) and obtains much better results than by using plain historical simulation (Živković, 2006). Jurun et al. conclude that using assumption of heavy tailed distribution, such as Student's t-distribution in GARCH models, it is possible to forecast market risk much more precisely than under normality assumption (Jurun, Pivac \& Arnerić, 2007). Žiković also tests a wide range of VaR models on transitional markets of 2004 and $2007 \mathrm{EU}$ new member states as well as EU candidate states. Findings show that VaR models commonly used in developed stock markets are not well suited for measuring market risk in these markets (Živković, 2007). Kovačić successfully applied volatility forecasting models on the Macedonian stock market index in an effort to measure relationship between return and conditional volatility. (Kovačić, 2007). Terzić et al discovered the main commonly known stylized facts in the Serbian stock market data (Terzić \& Milojević, 2013). Radivojević et al. (2009) tested the applicability of parametric and non-parametric VaR method in Serbian stock market and founded that parametric VaR is reliable to assess market risk in BSE, but we think their findings are not correct, because they used short risk horizon and only one simplest backtest to validate VaR model (Radivojević, Milojković \& Stojković, 2010).

\section{Methodology}

From a mathematical point of view, $\mathrm{VaR}$ is the maximum loss that we will suffer over a certain time period with a predetermined probability level $q=1-\alpha$, called the confidence level. Formally, VaR at level $\mathrm{q}$ is the real number $x$ such that:

$P(X \leq x)=\int_{-\infty}^{x} f(x) d x=1-\alpha_{s} \quad x=\operatorname{VaR}(q)$

where $f(x)$ is the density function of the loss distribution. Generally speaking, with deviation from normality assumption, there are two main methods to construct VaR: parametric approach (analytical approach) and the nonparametric approach (historical simulation approach) (Dowd, 2002).

In the non-parametric approach, no particular distribution assumption is needed. VaR is calculated from the standard theory of order statistics (Kupiec, 1995). Under this approach, VaR is deduced from multiple runs that might be representative of the possible market price outcomes (Carol, 2008). HS method is the simplest method to construct VaR. It makes no presumptions about the distribution of returns. Instead, the distribution is constructed from the historical behavior of the portfolio returns (Anatolyev, 2006). The current portfolio is subjected to actual changes in the market factors during the past. The only assumption that is made in this method is that the past trends of profits and losses will continue in the future. Advantage of this method is because it is free from any estimating inaccuracy (Khindanova \& Rachev, 2000).

The RM approach is a particular, convenient case of the GARCH process. Variances are modeled using an exponentially weighted moving average (EWMA) forecast. The forecast is a weighted average of the previous forecast, with weight $\lambda$, and of the latest squared innovation, with weight (1$\lambda)$ : 
$\sigma_{t}^{2}=\lambda \sigma_{t-1}^{2}+(1-\lambda) r_{t-1}^{2}$

The $\lambda$ parameter, also called the decay factor, determines the relative weights placed on previous observations (Jorion, 2002). The EWMA model places geometrically declining weights on past observations, assigning greater importance to recent observations. The weights decrease at a geometric rate. The lower $\lambda$, the more quickly older observations are forgotten. Risk Metrics has chosen $\lambda=0.94$ for daily data and $\lambda=0.97$ for monthly data (Esch, Kieffer \& Lopez, 2005).

Throughout this paper, stock market returns are defined as continuously compounded or log returns (hereafter returns) at time $t, r_{t}$, calculated as follows:

$r_{t}=\log \left(P_{t} / P_{t-1}\right)=\ln P_{t}-\ln P_{t-1}$

where $\mathrm{P}_{\mathrm{t}}$ i $\mathrm{P}_{\mathrm{t}-1}$ are the closing market indices at days $t$ and $t-1$, respectively.

To assess the accuracy of the VaR model we need to implement backtests of model. In another word, an accurate VaR measure should satisfy both the unconditional coverage property and independent property. The unconditional coverage property means that the probability of realization of a loss in excess of the estimated $\operatorname{VaR}_{t}(\alpha)$ must be exactly $\alpha \%$ (i.e., $\left.P\left(I_{t}(\alpha)=1\right)=\alpha\right)($ Campbell, 2005).

Failure of unconditional coverage means that the calculated VaR does not measure the risk accurately. The independent property means that previous VaR violations do not presage future VaR violations. The independence property refers to clustering of exception. (Khindanova \& Rachev, 2000).

\section{Data and Empirical Analysis}

The data used in the paper are the daily closing blue chips market indices Belex 15, DAX, PX, SAX and S\&P 500. Considering the fact that Serbian stock exchange index (Belex 15) started on 4 October 2005. We collected historical prices of indices from official stock exchanges during the period from $31 / 12 / 2005$ to $31 / 12 / 2012$, with 1760 observations.

Data sets for VaR estimation starts 500 days later and cover the period from 31/12/2007 to $31 / 12 / 2012$, in order to initialize the estimation. We include exponentially weighted moving average approach $(\lambda=0.94)$ and historical simulation approaches (500 days) to calculate $\mathrm{VaR}$ for two given different confidence levels $(95 \%, 99 \%)$. VaR models are calculated for a one-day holding period.

Through a simulation methodology, we attempt to determine how each VaR approach would have performed over a realistic range of indices over the sample period. In our empirical analysis, we investigate both in-sample (training) performance and out-of-sample (forecasting) performance based on the Unconditional coverage test, Christoffersen independent test and Conditional coverage test.

Backtesting diagnostics of $1260 \mathrm{VaR}$ forecasts for analyzed stock indices, at $95 \%$ and $99 \%$ confidence level are presented in tables 1 to 3. Detailed calculations of test results are presented in Appendix 1. We checked the unconditional coverage, independent and conditional coverage hypothesis using likelihood ratio test, which have a $\chi_{1}^{2}$ distribution with one degree of freedom and $\chi_{1}^{2}$ distribution with two degree of freedom for conditional coverage test. Rejected VaR models at 95\% and 99\% confidence level are given in table columns and marked with sign (-). Non rejection zone for analyzed VaR models are marked with (+). 
Table 1: Results of unconditional coverage backtest

\begin{tabular}{|c|c|c|c|c|c|c|c|c|c|c|}
\hline \multirow{2}{*}{$\begin{array}{c}\text { VaR } \\
\text { models }\end{array}$} & \multicolumn{2}{|c|}{ Belex 15 } & \multicolumn{2}{c|}{ S\&P 500 } & \multicolumn{2}{c|}{ DAX } & \multicolumn{2}{c|}{ PX } & \multicolumn{2}{c|}{ SAX } \\
\cline { 2 - 11 } & $95 \%$ & $99 \%$ & $95 \%$ & $99 \%$ & $95 \%$ & $99 \%$ & $95 \%$ & $99 \%$ & $95 \%$ & $99 \%$ \\
\hline HS 500 & + & + & + & - & + & - & + & + & + & + \\
\hline RM(0.94) & + & + & - & - & - & - & + & - & + & - \\
\hline
\end{tabular}

\section{Source: Authors}

For historical simulation there are two rejections in the VaR 99\%, while all VaR 95\% passed unconditional coverage tests. For Risk Metrics (0.94) number of rejections in the Var $99 \%$ is four and two in VaR 95\%. The superior performance of HS 500 model at 95\% and 99\% confidence level can be attributed to a presumed high volatility, which is a consequence of a long observation period of this model and occurrence of extreme events in the observation period. Based on the summary analysis, historical simulation seems to be superior in terms of unconditional coverage.

Table 2: Results of independence backtest

\begin{tabular}{|c|c|c|c|c|c|c|c|c|c|c|}
\hline \multirow{2}{*}{$\begin{array}{c}\text { VaR } \\
\text { models }\end{array}$} & \multicolumn{2}{|c|}{ Belex 15 } & \multicolumn{2}{c|}{ S\&P 500 } & \multicolumn{2}{c|}{ DAX } & \multicolumn{2}{c|}{ PX } & \multicolumn{2}{c|}{ SAX } \\
\cline { 2 - 11 } & $95 \%$ & $99 \%$ & $95 \%$ & $99 \%$ & $95 \%$ & $99 \%$ & $95 \%$ & $99 \%$ & $95 \%$ & $99 \%$ \\
\hline HS 500 & - & - & + & + & - & - & - & - & - & + \\
\hline RM(0.94) & - & - & + & + & + & + & - & - & + & + \\
\hline
\end{tabular}

\section{Source: Authors}

Table 2 presents the corresponding results of independence tests. In this table, Risk Metrics performs much better than historical simulation.

Accordingly property of independent, in three analyzed indices (S\&P 500, DAX and SAX) Risk Metrics VaR 95\% and 99\% accurately capture market risk exposure.

Belex 15 and PX failed both VaR (95\% and 99\%) models. The reason for these results should be found in potential clustering of volatility in given stock markets.

Table 3: Results of conditional coverage backtest

\begin{tabular}{|l|c|c|c|c|c|c|c|c|c|c|}
\multirow{2}{*}{$\begin{array}{c}\text { VaR } \\
\text { models }\end{array}$} & \multicolumn{2}{|c|}{ Belex 15 } & \multicolumn{2}{c|}{ S\&P 500 } & \multicolumn{2}{c|}{ DAX } & \multicolumn{2}{c|}{ PX } & \multicolumn{2}{c|}{ SAX } \\
\cline { 2 - 11 } & $95 \%$ & $99 \%$ & $95 \%$ & $99 \%$ & $95 \%$ & $99 \%$ & $95 \%$ & $99 \%$ & $95 \%$ & $99 \%$ \\
\hline HS 500 & - & - & + & - & - & - & - & - & - & + \\
\hline RM $(0.94)$ & - & - & - & - & + & + & - & - & + & - \\
\hline
\end{tabular}

Source: Authors

Table 3 displays corresponding results of the conditional coverage test. This test rejects VaR models for majority of indices, but in authors' opinion it provides a somewhat distorted image of the relative performance of VaR models.

As criteria for complete accuracy of market risk measurement we assume that VaR models must satisfy both unconditional coverage and independence property in model validation. 


\section{Conclusion}

In this paper we investigated the performance of VaR models that are widely used in the developed capital markets on daily indices returns from Serbia, Germany, Slovakia, Czech Republic and USA. All analyzed equity markets in observed window length have become increasingly volatile due to the emerging financial crisis that started at the end of the second quarter of 2007, and culminated in the bankruptcy of Lehman Brothers in 2008. In this period, the markets were characterized by unusually high volatility levels and huge losses. As a result of this event VaR models that are applied in the work not properly predict market risk, even in the most efficient capital markets such as the NYSE. Results in EU capital markets suggests that market risk is also underestimated, which leads us to the conclusion that the sources of financing companies are primarily oriented to the banking sector and not in equity financing. An additional reason for the poor performance of VaR models in the EU states and Serbia is the European debt crisis, which is currently present in most of the countries in the Eurozone, and it also has direct implications in Serbian financial system. This influence is reflected in the withdrawal and decreasing activity of the investors who are investing in these stock markets. In case of Serbian stock market the situation is more complex in field of market risk measurement because returns of index Belex 15 are characterized by autocorrelation and heteroskedasticity, which considerably complicates VaR estimation. Since neither one of the tested models did not fully satisfy both criteria of backtesting VaR models, we can conclude that all the applied models significantly underestimate market risk in observed period. We believe that for the relevant assessment of market risk exposure in all analyzed markets, it is necessary to use more complex measures of risk such as extreme value theory, in order to capture and properly quantify market risk based on all relevant risk factors. Additionally, in the case of Serbia it is necessary to take into consideration more computationally and intellectually demanding VaR models.

\section{References}

Anatolyev, S. (2006). Nonparametric retrospection and monitoring of predictability of financial returns. Moscow, Russia: Centre for Economic and Financial Research at New Economic School.

Campbell, S. (2005). A review of backtesting and backtesting procedures. Washington, D.C.: Finance and Economics Discussion Series, Federal Reserve Board.

Carol, A. (2008). Value at Risk Models. Chichester, England: John Wiley \& Sons.

Dowd, K. (2002). Measuring Market Risk. Chichester, England: John Wiley \& Sons.

Esch, L., Kieffer, R. \& Lopez, T. (2005). Asset and Risk Managment. New York, NY: The Wiley Finance.

Jorion, P. (2002). Value at Risk : the new benchmark for managing financial risk. New York, NY: McGraw-Hill. PMid:12050528

Jurun, E., Pivac, S. \& Arnerić, J. (2007). Historical and Prognostic Risk Measuring Across Stocks and Markets. Journal of WSEAS Transactions on Business and Economic, Vol. 4., No. 8, 126-134.

Khindanova, I. \& Rachev, S. (2000). Value at risk: Recent Advances. In Anastassiou, G. (Ed.), Handbook of Analytic Computational Methods in Applied Mathematics (p. 801 - 858). Boca Raton, FL: Chapman and Hall/CRC Press LLC. http://dx.doi.org/10.1201/9781420036053.ch18 
Kovačić, Z. (2007). Forecasting volatility: Evidence from the Macedonian stock exchange. MPRA Paper No. 5319. Munich, Germany: University Library of Munich. Retrieved from http://mpra.ub.unimuenchen.de

Kupiec, P. (1995). Techniques for verifying the accuracy of risk managment models. Journal of Derivates, Vol. 3, No. 2, 73-84. http://dx.doi.org/10.3905/jod.1995.407942

Milojević, M. (2008). Impact macroeconomic factors on Belgrade Stock Exchange. Belgrade, Serbia: Singidunum University.

Radivojević, N., Milojković, D. \& Stojković, D. (2010). Testiranje aplikativnosti parametarske i neparametarske metode vrednosti pri riziku na trzhishtu kapitala Srbije [Testing the Applicability of parametric and nonparametric methods of Value at Risk at the Serbian Capital Market]. Bankarstvo, Vol. 2010, No.11/12, 46-61.

Terzić, I. \& Milojević, M. (in press). Kvalitet metoda merenja trzhishnog rizika na trzhishtu kapitala srbije i nemaczke [Quality of Market Risk Measures on Serbian and German Capital Market]. Proceedings of International science conference Quality leads to Europe held in Bijeljina, Bosnia and Herzegovina April 1, 2013. PMid:19461241

Živković, S. (2006). Applying Hybrid Approach to calculating VaR in Croatia. Proceedings of the International Conference „From Transition to Sustainable Development: The Path to European Integration " held in Sarajevo, Bosnia and Herzegovina, October 12-13, 2006. (p. 50-71). Sarajevo, Bosnia: Faculty of Economics in Sarajevo.

Živković, S. (2006). Implications of Measuring VaR using Historical simulation; an Example of Zagreb Stock Exchange index - CROBEX. In Roufagalas, J. (Ed.), Resource Allocation and Institutions: Explorations in Economics, Finance and Law (p. 367-389). Athens, Greece: Athens Institute for Education and Research.

Živković, S. (2007). Testing Popular VaR Models in EU New Member and Candidate States. Journal of Economics and Business, Vol. 25, No. 2, 325-346. Rijeka, Croatia: Rijeka Faculty of Economics. 
CBU INTERNATIONAL CONFERENCE ON INTEGRATION AND INNOVATION IN SCIENCE AND EDUCATION

\section{APPENDIX 1}

Backtesting results and diagnostics of $1260 \mathrm{VaR}$ forecasts for analyzed indices daily log returns,

95\% and 99\% confidence level. Between 31. 12. 2005 - 31. 12. 2012.

\begin{tabular}{|c|c|c|c|c|}
\hline \multirow{3}{*}{ DAX } & \multicolumn{4}{|c|}{ Test Statistics } \\
\hline & \multicolumn{2}{|c|}{ RiskMetrics } & \multicolumn{2}{|c|}{ Historical Simulation } \\
\hline & $1 \%$ & $5 \%$ & $1 \%$ & $5 \%$ \\
\hline $\mathrm{T}_{0}$ & 1235 & 1181 & 1240 & 1177 \\
\hline $\mathrm{T}_{1}$ & 25 & 79 & 20 & 83 \\
\hline$T_{00}$ & 1210 & 1105 & 1222 & 1110 \\
\hline$T_{01}$ & 25 & 76 & 18 & 67 \\
\hline$T_{10}$ & 25 & 76 & 18 & 67 \\
\hline$T_{11}$ & 0 & 3 & 2 & 16 \\
\hline$\hat{\pi}$ & $1,98 \%$ & $6,27 \%$ & $1,59 \%$ & $6,59 \%$ \\
\hline$L(\hat{\pi})$ & $4,90 \mathrm{E}-54$ & $5,93 \mathrm{E}-129$ & $2,49 E-45$ & $1,32 \mathrm{E}-133$ \\
\hline$L(p)$ & 4,07E-56 & $8,13 \mathrm{E}-130$ & $3,87 \mathrm{E}-46$ & $6,24 \mathrm{E}-135$ \\
\hline$\hat{\pi}_{01}$ & $2,02 \%$ & $6,44 \%$ & $1,45 \%$ & $5,69 \%$ \\
\hline$\hat{\pi}_{11}$ & $0,00 \%$ & $3,80 \%$ & $10,00 \%$ & $19,28 \%$ \\
\hline$L\left(\hat{\pi}_{1}\right)$ & $0,00 \mathrm{E}+00$ & 9,79E-129 & $2,13 \mathrm{E}-44$ & $4,80 \mathrm{E}-13 \mathrm{C}$ \\
\hline $\mathbf{L R}_{\mathrm{uc}}$ & 9,583 & 3,972 & 3,725 & 6,103 \\
\hline $\mathbf{L R}_{\text {ind }}$ & 0,000 & 1,003 & 4,296 & 16,397 \\
\hline $\mathbf{L R}_{\mathrm{cc}}$ & 0,000 & 4,976 & 8,021 & 22,500 \\
\hline \multirow{3}{*}{$\begin{array}{c}\text { BELEX } \\
15\end{array}$} & \multicolumn{4}{|c|}{ Test Statistics } \\
\hline & \multicolumn{2}{|c|}{ RiskMetrics } & \multicolumn{2}{|c|}{ Historical Simulation } \\
\hline & $1 \%$ & $5 \%$ & $1 \%$ & $5 \%$ \\
\hline$T_{0}$ & 1242 & 1202 & 1243 & 1208 \\
\hline $\mathrm{T}_{1}$ & 18 & 58 & 17 & 52 \\
\hline$T_{00}$ & 1228 & 1155 & 1232 & 117 \\
\hline$T_{01}$ & 14 & 47 & 11 & 36 \\
\hline$T_{10}$ & 14 & 47 & 11 & 36 \\
\hline$T_{11}$ & 4 & 11 & 6 & 16 \\
\hline$\hat{\pi}$ & $1,43 \%$ & $4,60 \%$ & $1,35 \%$ & $4,13 \%$ \\
\hline$L(\hat{\pi})$ & $1,06 \mathrm{E}-41$ & $7,20 \mathrm{E}-103$ & $7,56 \mathrm{E}-40$ & $7,98 \mathrm{E}-95$ \\
\hline$L(p)$ & $3,79 E-42$ & $5,81 \mathrm{E}-103$ & $3,75 \mathrm{E}-40$ & $2,73 \mathrm{E}-95$ \\
\hline$\hat{\pi}_{01}$ & $1,13 \%$ & $3,91 \%$ & $0,88 \%$ & $2,98 \%$ \\
\hline$\hat{\pi}_{11}$ & $22,22 \%$ & $18,97 \%$ & $35,29 \%$ & $30,77 \%$ \\
\hline $\mathrm{L}\left(\hat{\pi}_{1}\right)$ & $3,48 E-38$ & $3,90 \mathrm{E}-99$ & $7,36 \mathrm{E}-33$ & $5,42 \mathrm{E}-85$ \\
\hline $\mathbf{L R}_{\mathrm{uc}}$ & 2,064 & 0,429 & 1,399 & 2,144 \\
\hline $\mathbf{L R}_{\text {ind }}$ & 16,185 & 17,194 & 32,182 & 45,277 \\
\hline $\mathbf{L R}_{\mathrm{cc}}$ & 18,248 & 17,623 & 33,582 & 47,42 \\
\hline
\end{tabular}

\begin{tabular}{|c|c|c|c|c|}
\hline \multirow{3}{*}{ S\&P 500} & \multicolumn{4}{|c|}{ Test Statistics } \\
\hline & \multicolumn{2}{|c|}{ RiskMetrics } & \multicolumn{2}{|c|}{ Historical Simulation } \\
\hline & \begin{tabular}{l|l}
$1 \%$ \\
\end{tabular} & $5 \%$ & $1 \%$ & $5 \%$ \\
\hline$T_{0}$ & 1229 & 1181 & 1234 & 1182 \\
\hline $\mathrm{T}_{1}$ & 31 & 79 & 26 & 78 \\
\hline$T_{00}$ & 1199 & 1104 & 1210 & 1112 \\
\hline$T_{01}$ & 30 & 77 & 24 & 70 \\
\hline $\mathrm{T}_{10}$ & 30 & 77 & 24 & 70 \\
\hline$T_{11}$ & 1 & 2 & 2 & 8 \\
\hline$\hat{\pi}$ & $2,46 \%$ & $6,27 \%$ & $2,06 \%$ & $6,19 \%$ \\
\hline$L(\hat{\pi})$ & $6,68 \mathrm{E}-64$ & 5,93E-129 & $1,01 \mathrm{E}-55$ & $8,92 \mathrm{E}-128$ \\
\hline$L(p)$ & $4,32 \mathrm{E}-68$ & $8,13 \mathrm{E}-130$ & $4,11 \mathrm{E}-58$ & $1,55 \mathrm{E}-128$ \\
\hline$\hat{\pi}_{01}$ & $2,44 \%$ & $6,52 \%$ & $1,94 \%$ & $5,92 \%$ \\
\hline$\hat{\pi}_{11}$ & $3,23 \%$ & $2,53 \%$ & $7,69 \%$ & $10,26 \%$ \\
\hline$L\left(\hat{\pi}_{1}\right)$ & $6,92 \mathrm{E}-64$ & $2,09 \mathrm{E}-128$ & $3,55 \mathrm{E}-55$ & $2,45 \mathrm{E}-127$ \\
\hline $\mathbf{L R}_{\mathrm{uc}}$ & 19,291 & 3,972 & 11,013 & 3,506 \\
\hline $\mathbf{L R}_{\text {ind }}$ & 0,071 & 2,519 & 2,510 & 2,023 \\
\hline $\mathbf{L R}_{\mathrm{cc}}$ & 19,362 & 6,491 & 13,523 & 5,530 \\
\hline \multirow{3}{*}{ PX } & \multicolumn{4}{|c|}{ Test Statistics } \\
\hline & \multicolumn{2}{|c|}{ RiskMetrics } & \multicolumn{2}{|c|}{ Historical Simulation } \\
\hline & $1 \%$ & $5 \%$ & $1 \%$ & $5 \%$ \\
\hline$T_{0}$ & 1235 & 1186 & 1241 & 1183 \\
\hline $\mathbf{T}_{1}$ & 25 & 74 & 19 & 77 \\
\hline$T_{00}$ & 1214 & 1122 & 1226 & 1127 \\
\hline$T_{01}$ & 21 & 64 & 15 & 56 \\
\hline$T_{10}$ & 21 & 64 & 15 & 56 \\
\hline$T_{11}$ & 4 & 10 & 4 & 21 \\
\hline$\hat{\pi}$ & $1,98 \%$ & $5,87 \%$ & $1,51 \%$ & $6,11 \%$ \\
\hline$L(\hat{\pi})$ & 4,90E-54 & $5,26 \mathrm{E}-123$ & 1,59E-43 & $1,36 \mathrm{E}-126$ \\
\hline$L(p)$ & $4,07 \mathrm{E}-56$ & $2,01 \mathrm{E}-123$ & $3,83 \mathrm{E}-44$ & $2,94 \mathrm{E}-127$ \\
\hline$\hat{\pi}_{01}$ & $1,70 \%$ & $5,40 \%$ & $1,21 \%$ & $4,73 \%$ \\
\hline$\hat{\pi}_{11}$ & $16,00 \%$ & $13,51 \%$ & $21,05 \%$ & $27,27 \%$ \\
\hline$L\left(\hat{\pi}_{1}\right)$ & $1,06 \mathrm{E}-51$ & $1,25 \mathrm{E}-121$ & $3,26 \mathrm{E}-40$ & $3,03 \mathrm{E}-118$ \\
\hline $\mathbf{L R}_{\mathrm{uc}}$ & 9,583 & 1,919 & 2,841 & 3,068 \\
\hline $\mathbf{L R}_{\text {ind }}$ & 10,755 & 6,331 & 15,257 & 38,441 \\
\hline $\mathbf{L R}_{\mathrm{cc}}$ & 20,338 & 8,250 & 18,098 & 41,509 \\
\hline
\end{tabular}

\begin{tabular}{|c|c|c|c|c|}
\hline \multirow{3}{*}{ SAX } & \multicolumn{4}{|c|}{ Test Statistics } \\
\hline & \multicolumn{2}{|c|}{ RiskMetrics } & \multicolumn{2}{|c|}{ Historical Simulation } \\
\hline & $1 \%$ & $5 \%$ & $1 \%$ & $5 \%$ \\
\hline$T_{0}$ & 1224 & 1191 & 1242 & 1185 \\
\hline$T_{1}$ & 36 & 69 & 18 & 75 \\
\hline$T_{00}$ & 1189 & 1125 & 1224 & 1120 \\
\hline$T_{01}$ & 35 & 66 & 18 & 65 \\
\hline$T_{10}$ & 35 & 66 & 18 & 65 \\
\hline$T_{11}$ & 1 & 3 & 0 & 10 \\
\hline$\hat{\pi}$ & $2,86 \%$ & $5,48 \%$ & $1,43 \%$ & $5,95 \%$ \\
\hline$L(\hat{\pi})$ & 1,01E-71 & $6,68 \mathrm{E}-117$ & $1,06 \mathrm{E}-41$ & $3,30 \mathrm{E}-124$ \\
\hline$L(p)$ & $4,54 \mathrm{E}-78$ & $4,99 \mathrm{E}-117$ & $3,79 E-42$ & $1,06 \mathrm{E}-124$ \\
\hline$\hat{\pi}_{01}$ & $2,86 \%$ & $5,54 \%$ & $1,45 \%$ & $5,49 \%$ \\
\hline$\hat{\pi}_{11}$ & $2,78 \%$ & $4,35 \%$ & $0,00 \%$ & $13,33 \%$ \\
\hline$L\left(\hat{\pi}_{1}\right)$ & $1,01 \mathrm{E}-71$ & $7,35 \mathrm{E}-117$ & $0,00 \mathrm{E}+00$ & $6,56 \mathrm{E}-123$ \\
\hline $\mathbf{L R}_{\mathrm{uc}}$ & 29,229 & 0,584 & 2,064 & 2,274 \\
\hline $\mathbf{L R}_{\text {ind }}$ & 0,001 & 0,192 & 0,000 & 5,978 \\
\hline $\mathbf{L R}_{\mathrm{cc}}$ & 29,230 & 0,776 & 0,000 & 8,252 \\
\hline
\end{tabular}

